\title{
Review
}

\section{Present status of Accelerator-Based BNCT}

\author{
Andres Juan Kreiner ${ }^{a, b, c, *}$, Javier Bergueiro ${ }^{a}$, Daniel Cartelli ${ }^{a, b, c}$, \\ Matias Baldo ${ }^{a}$, Walter Castell ${ }^{a}$, Javier Gomez Asoia ${ }^{a}$, Javier Padulo ${ }^{a}$, \\ Juan Carlos Suárez Sandín ${ }^{a}$, Marcelo Igarzabal $^{a}$, Julian Erhardt ${ }^{a}$, \\ Daniel Mercuri ${ }^{a}$, Alejandro A. Valda ${ }^{a, b}$, Daniel M. Minsky ${ }^{a, b, c}$, \\ Mario E. Debray ${ }^{a, b}$, Hector R. Somacal ${ }^{a, b}$, María Eugenia Capoulat ${ }^{a, b, c}$, \\ María S. Herrera ${ }^{a, b, c}$, Mariela F. del Grosso ${ }^{a, c}$, Leonardo Gagetti ${ }^{a, b, c}$, \\ Manuel Suarez Anzorena ${ }^{a}$, Nicolas Canepa ${ }^{a}$, Nicolas Real ${ }^{a}$, Marcelo Gun ${ }^{d}$, \\ Hernán Tacca ${ }^{d}$ \\ a Gerencia de Investigación y Aplicaciones, CNEA, Av Gral Paz 1499, 1650 San Martin, Argentina \\ b Escuela de Ciencia y Tecnología, Universidad de San Martín, Argentina \\ c CONICET, Argentina \\ d Faculty of Engineering, UBA, Argentina
}

\section{A R T I C L E I N F O}

\section{Article history:}

Received 7 April 2014

Received in revised form

18 October 2014

Accepted 7 November 2014

Available online 12 December 2014

\section{Keywords:}

Accelerator-Based BNCT

Different nuclear reactions and

accelerator types

Worldwide activity

\begin{abstract}
A B S T R A C T
Aim: This work aims at giving an updated report of the worldwide status of Accelerator-Based BNCT (AB-BNCT).

Background: There is a generalized perception that the availability of accelerators installed in hospitals, as neutron sources, may be crucial for the advancement of BNCT. Accordingly, in recent years a significant effort has started to develop such machines.

Materials and methods: A variety of possible charged-particle induced nuclear reactions and the characteristics of the resulting neutron spectra are discussed along with the worldwide activity in suitable accelerator development.

Results: Endothermic ${ }^{7} \mathrm{Li}(\mathrm{p}, \mathrm{n})^{7} \mathrm{Be}$ and ${ }^{9} \mathrm{Be}(\mathrm{p}, \mathrm{n}){ }^{9} \mathrm{~B}$ and exothermic ${ }^{9} \mathrm{Be}(\mathrm{d}, \mathrm{n})^{10} \mathrm{~B}$ are compared. In addition to having much better thermo-mechanical properties than $\mathrm{Li}$, Be as a target leads to stable products. This is a significant advantage for a hospital-based facility. ${ }^{9} \mathrm{Be}(\mathrm{p}, \mathrm{n})^{9} \mathrm{~B}$ needs at least 4-5 MeV bombarding energy to have a sufficient yield, while ${ }^{9} \mathrm{Be}(\mathrm{d}, \mathrm{n})^{10} \mathrm{~B}$ can be utilized at about $1.4 \mathrm{MeV}$, implying the smallest possible accelerator. This reaction operating with a thin target can produce a sufficiently soft spectrum to be viable for AB-BNCT. The machines considered are electrostatic single ended or tandem accelerators or radiofrequency quadrupoles plus drift tube Linacs.

Conclusions: ${ }^{7} \mathrm{Li}(\mathrm{p}, \mathrm{n})^{7} \mathrm{Be}$ provides one of the best solutions for the production of epithermal neutron beams for deep-seated tumors. However, a Li-based target poses significant technological challenges. Hence, Be has been considered as an alternative target, both in
\end{abstract}

\footnotetext{
* Corresponding author at: Gerencia de Investigación y Aplicaciones, CNEA, Av Gral Paz 1499, B1650KNA San Martin, Prov. Buenos Aires, Argentina. Tel.: +54 01167727151.

E-mail address: kreiner@tandar.cnea.gov.ar (A.J. Kreiner).
}

http://dx.doi.org/10.1016/j.rpor.2014.11.004

1507-1367/@ 2014 Greater Poland Cancer Centre. Published by Elsevier Sp. z o.o. All rights reserved. 
combination with $(\mathrm{p}, \mathrm{n})$ and $(\mathrm{d}, \mathrm{n})$ reactions. ${ }^{9} \mathrm{Be}(\mathrm{d}, \mathrm{n})^{10} \mathrm{~B}$ at $1.4 \mathrm{MeV}$, with a thin target has been shown to be a realistic option for the treatment of deep-seated lesions.

(C) 2014 Greater Poland Cancer Centre. Published by Elsevier Sp. z o.o. All rights reserved.

\section{Introduction}

Accelerator-Based BNCT (AB-BNCT) is being viewed worldwide as the future modality to start the era of in-hospital facilities. There are projects in Russia, UK, Italy, Japan, Israel, and Argentina to develop AB-BNCT around different types of accelerators which will be briefly reviewed.

In this article a variety of possible charged-particle induced nuclear reactions and the characteristics of the resulting neutron spectra will be discussed along with different particle accelerators as neutron-producing sources. The focus is in the treatment of deep-seated tumors which require an epithermal neutron spectrum (the epithermal range is defined as ranging from $0.5 \mathrm{eV}$ to $10 \mathrm{keV}$ ) at the patient's entrance. Likewise the epithermal neutron flux has to be larger than $10^{9} \mathrm{n} / \mathrm{cm}^{2} \mathrm{~s}$. Present efforts to develop such facilities worldwide will be described.

\section{Overview of accelerator development for AB-BNCT worldwide}

Presently there are several initiatives to develop AB-BNCT. Table 1 gives the present status and performance of the different accelerators for AB-BNCT facilities worldwide. Some of the accelerators are already developed and some are under construction. We include only proton or deuteron machines. There is a first group of accelerators which are already operational, they are mainly low energy machines working stably on relatively low currents and using the ${ }^{7} \mathrm{Li}(\mathrm{p}, \mathrm{n})$ reaction although some of them may be upgradable. The exception is the KURRI project which uses a $30 \mathrm{MeV}$ proton cyclotron and Be as a neutron producing target, having to deal with a very hard neutron spectrum. The last three rows describe facilities under development conceived to operate at higher current levels.

\section{Different neutron-producing reactions of interest for $\mathrm{AB}-\mathrm{BNCT}$}

Table 2 lists the reactions considered in this work for AB-BNCT along with some of their properties. It is worth remembering that the Coulomb barriers of protons on common structural materials, like $\mathrm{Fe}$ and $\mathrm{Cu}$, are about $5 \mathrm{MeV}$ and hence, in order to avoid inducing radioactivity, it would be desirable to work below that threshold.

\subsection{The endothermic ${ }^{7} \mathrm{Li}(p, n)^{7} \mathrm{Be}$ and ${ }^{9} \mathrm{Be}(p, n)^{9} \mathrm{~B}$ reactions}

The most popular endothermic reaction for AB-BNCT is ${ }^{7} \mathrm{Li}(\mathrm{p}, \mathrm{n})^{7} \mathrm{Be}$. The $\mathrm{Q}$-value is $-1.644 \mathrm{MeV}$ and the threshold energy for the impinging proton is $1.880 \mathrm{MeV}$. At this bombarding energy the neutron has about $30 \mathrm{keV}$ kinetic energy in the lab frame. This energy is not very far from the epithermal regime. There are in fact proposals to work in this regime. ${ }^{9,10}$ At $1.91 \mathrm{MeV}$ the maximum and average neutron energies are 105 and $42 \mathrm{keV}$ and the maximum and average emission angles are 60 and $28^{\circ} .{ }^{11}$ This angular confinement ("kinematic collimation") allows for a very efficient utilization of the neutrons in terms of the ratio of utilized neutrons/produced neutrons.

In addition to the kinematics of the reaction, it is important to examine the cross section as a function of the proton energy in the lab which will determine the actual neutron production. ${ }^{7} \mathrm{Li}(\mathrm{p}, \mathrm{n})^{7} \mathrm{Be}$ shows a very steep rise from the threshold on and a small plateau starting at about $1.93 \mathrm{MeV}$ (reaching a value of $270 \mathrm{mb}$ ) before the pronounced resonance at $2.25 \mathrm{MeV}$ (reaching $580 \mathrm{mb}$ ). ${ }^{12}$ This translates, as examples, into the following values for total thick target Li neutron yield: $6.3 \times 10^{9} \mathrm{n} /(\mathrm{mA} \mathrm{s})$ for $1.89 \mathrm{MeV}$ and $5.8 \times 10^{11} \mathrm{n} /(\mathrm{mAs})$ for $2.3 \mathrm{MeV}$ proton bombarding energy ${ }^{11}$ (see also Table 3 ).

Working near-threshold would require very little moderation (at $1.89 \mathrm{MeV}$ the maximum neutron energy is $67 \mathrm{keV}$ ) but at the same time would impose a very stringent demand on the energy/voltage stability of the accelerator of $0.1 \%$ in order to maintain the production rate sufficiently constant. In our studies ${ }^{13}$ we have concluded that $2.3 \mathrm{MeV}$ incident proton energy is a very good compromise between an already significant value of the production cross section and still a sufficiently low maximum neutron energy of $573 \mathrm{keV}$. The minimum neutron energy is $141 \mathrm{keV}$ (at an angle of $180^{\circ}$ ) and the average energy is $233 \mathrm{keV}$ for a thick target (a thick target is defined as one in which the projectile looses enough energy to cross below the reaction threshold).

To use the ${ }^{7} \mathrm{Li}+\mathrm{p}$ reaction would hence demand an accelerator of 2.3 MV "effective" voltage if it is a single-ended machine (the term effective is to indicate that it is not necessarily an electrostatic voltage, e.g., if the accelerator is electrodynamic) or 1.15 MV if it is a tandem (we shall discuss the different accelerator options later on). In addition, the necessary therapeutic thermal neutron flux of the order of $10^{9} \mathrm{ncm}^{-2} \mathrm{~s}^{-1}$ at the tumor position demands relatively high currents (order of tens of mA's needed due to the thick moderator) and here is where the real challenge lies. The high power density deposited in the target material, here metallic Li in the most efficient case, is very high (of the order of $1 \mathrm{~kW} \mathrm{~cm}^{-2}$ ) and its cooling represents a challenging technological problem in itself, particularly in view of the rather low melting point $(180.5 \mathrm{~K})$ and thermal conductivity $\left(85 \mathrm{~W} \mathrm{~m}^{-1} \mathrm{~K}^{-1}\right)$ of Li. The difficulty in keeping the target solid has led to the consideration of a liquid Li target. ${ }^{5,17}$ Another non-negligible complication is the fact that the residual nucleus ${ }^{7} \mathrm{Be}$ is radioactive, implying risks associated to target activation and possible system contamination. 


\begin{tabular}{|c|c|c|c|c|c|}
\hline Institute-location & Machine (status) & $\begin{array}{l}\text { Target and } \\
\text { reaction }\end{array}$ & $\begin{array}{c}\text { Beam energy neutron } \\
\text { energy }(\mathrm{MeV})\end{array}$ & Beam current $(\mathrm{mA})$ & Reference \\
\hline $\begin{array}{l}\text { Budker Institute } \\
\text { Russia }\end{array}$ & Vacuum insulated Tandem (ready) & Solid ${ }^{7} \operatorname{Li}(p, n)$ & $\begin{array}{l}2.0 \\
<1\end{array}$ & 2 & Aleynik et al. $2011^{1}$ \\
\hline $\begin{array}{l}\text { IPPE-Obninsk } \\
\text { Russia }\end{array}$ & Cascade generator KG-2.5 (ready) & Solid ${ }^{7} \operatorname{Li}(p, n)$ & $\begin{array}{l}2.3 \\
<1\end{array}$ & 3 & Kononov et al. $2004^{2}$ \\
\hline $\begin{array}{l}\text { Birmingham Univ. } \\
\text { UK }\end{array}$ & Dynamitron (ready) & Solid ${ }^{7} \operatorname{Li}(\mathrm{p}, \mathrm{n})$ & $\begin{array}{l}2.8 \\
<1.1\end{array}$ & 1 & Ghani et al. $2008^{3}$ \\
\hline $\begin{array}{l}\text { KURRI } \\
\text { Japan }\end{array}$ & Cyclotron (clinical trials started) & ${ }^{9} \mathrm{Be}(\mathrm{p}, \mathrm{n})$ & $\begin{array}{l}30 \\
<28\end{array}$ & 1 & Tanaka et al. $2011^{4}$ \\
\hline $\begin{array}{l}\text { Soreq } \\
\text { Israel }\end{array}$ & RFQ-DTL ${ }^{a}$ (ready) & Liquid ${ }^{7} \operatorname{Li}(p, n)$ & $\begin{array}{l}4 \\
<2.3\end{array}$ & 2 & Halfon et al. $2011^{5}$ \\
\hline $\begin{array}{l}\text { INFN Legnaro } \\
\text { Italy }\end{array}$ & RFQ (under construction) & ${ }^{9} \mathrm{Be}(\mathrm{p}, \mathrm{n})$ & $\begin{array}{l}4-5 \\
<2-3\end{array}$ & 30 & Ceballos et al. $2011^{6}$ \\
\hline $\begin{array}{c}\text { Tsukuba } \\
\text { Japan }\end{array}$ & RFQ-DTL (under construction) & ${ }^{9} \mathrm{Be}(\mathrm{p}, \mathrm{n})$ & $\begin{array}{l}8 \\
<6\end{array}$ & 10 & Kumada et al. $2011^{7}$ \\
\hline $\begin{array}{l}\text { CNEA } \\
\text { Buenos Aires }\end{array}$ & Single ended $\mathrm{ESQ}^{\mathrm{b}}$ & ${ }^{9} \mathrm{Be}(\mathrm{d}, \mathrm{n})$ & $\begin{array}{l}1.4 \\
<5.7\end{array}$ & 30 & $\begin{array}{l}\text { Kreiner et al. 2011, } \\
2013^{8}\end{array}$ \\
\hline Argentina & Tandem ESQ (under construction) & Solid ${ }^{7} \operatorname{Li}(p, n)$ & $\begin{array}{l}2.5 \\
<1\end{array}$ & 30 & \\
\hline
\end{tabular}


Table 2 - Nuclear reaction properties for targets of ${ }^{7} \mathrm{Li}$ and ${ }^{9} \mathrm{Be}$.

\begin{tabular}{llc} 
Reaction & \multicolumn{1}{c}{$\begin{array}{c}\text { Reaction } \\
\text { threshold }(\mathrm{MeV})\end{array}$} & $\begin{array}{c}\text { Radioactive } \\
\text { products }\end{array}$ \\
\hline$\left.{ }^{7} \mathrm{Li}(\mathrm{p}, \mathrm{n})\right)^{7} \mathrm{Be}$ & 1.88 & Yes \\
${ }^{9} \mathrm{Be}(\mathrm{p}, \mathrm{n}){ }^{9} \mathrm{~B}$ & 2.06 & $\mathrm{No}^{\mathrm{a}}$ \\
${ }^{9} \mathrm{Be}(\mathrm{d}, \mathrm{n})^{10} \mathrm{~B}$ & 0 (exothermic) & No \\
${ }^{9} \mathrm{Be}(\mathrm{d}, \mathrm{n})^{10} \mathrm{~B}^{*}$ & $1^{\mathrm{c}}$ & No \\
\hline
\end{tabular}

a Very short lived activity with no gamma emission.

b Average energy of emitted neutrons is $1.7 \mathrm{MeV}$.

c Population of excited states at $\approx 5.1 \mathrm{MeV}$ in ${ }^{10} \mathrm{~B}$. The reaction for population of these states has an effective threshold of $\approx 1 \mathrm{MeV}$.

Finally a brief comment about the other endothermic reaction induced by protons on Be. As shown in Table 3, the yield of the ${ }^{9} \mathrm{Be}(\mathrm{p}, \mathrm{n}){ }^{9} \mathrm{~B}$ reaction at $2.5 \mathrm{MeV}$ is much lower than the one of the protons on $\mathrm{Li}$ at the same energy. In order to get a comparable production one has to go to energies of about $4 \mathrm{MeV}$. At these bombarding energies the neutron energy is significantly higher than for the $\mathrm{p}+\mathrm{Li}$ case (up to $2.1 \mathrm{MeV}$ ) and in addition the effective voltage has to be $4 \mathrm{MV}$ which increases the cost of the accelerator significantly. Such a facility is actively pursued by the LNL-INFN Italian group ${ }^{6}$ to generate thermal neutrons and treat superficial lesions. There are several other projects based on this reaction. There is a $30 \mathrm{MeV}$ proton cyclotron installed at Kyoto University, ${ }^{4}$ which produces very high energy neutrons of up to $28 \mathrm{MeV}$, likely to activate parts of the facility. There is also an RFQ-DTL being installed at Ibaraki prefecture, near Tsukuba, intended to work with an $8 \mathrm{MeV}$ proton beam ${ }^{7}$ (see Table 1), producing neutrons of up to $6 \mathrm{MeV}$.

\subsection{Exothermic deuteron-induced reactions}

The use of the ${ }^{9} \mathrm{Be}(\mathrm{d}, \mathrm{n}){ }^{10} \mathrm{~B}$ leads to very acceptable results for the treatment of superficial lesions ${ }^{18}$ and will be discussed in the following sentences. This reaction has been mentioned in the past as a possible source of neutrons for BNCT. ${ }^{14}$ Being an exothermic reaction it has the advantage of no threshold and a significant neutron production cross section at relatively low energies. Its drawback is its high Q-value (4.36 MeV) which leads to significant fast neutron production (about $1.7 \mathrm{MeV}$ average neutron energy for $1.5 \mathrm{MeV}$ bombarding energy, see Table 2). There is however a very interesting feature of this reaction noted some time ago. ${ }^{19}{ }^{10} \mathrm{~B}$, the heavy product in the ${ }^{9} \mathrm{Be}(\mathrm{d}, \mathrm{n})$ reaction, being a doubly odd nuclide, is already a relatively complex nucleus. It has a number of excited states, but in particular it has one at $5.11 \mathrm{MeV}$ which is strongly populated as soon as it becomes energetically accessible. Hence, for that state, the reaction becomes effectively endothermic and the emitted neutrons have very small energies depending on the exact bombarding energy. The threshold energy is $0.915 \mathrm{MeV}$. This fact opens the possibility for suppressing a significant part of the fast neutrons produced in this reaction. If one takes a thin Be target (about $7.4 \mu \mathrm{m}$ thick), so that a $1.45 \mathrm{MeV}$ deuteron looses about $400 \mathrm{keV}$, the whole fast neutron production stemming from $1.05 \mathrm{MeV}$ downwards is suppressed while the low energy neutron production remains intact. Under these circumstances, a thin Be target and heavy water moderation (of $15 \mathrm{~cm}$ depth) with a $20 \mathrm{~mA}$ beam allows a single-session BNCT treatment ${ }^{18}$ in $48 \mathrm{~min}$. For superficial lesions a single ended machine of $1.2 \mathrm{MV}$ in the terminal would suffice, while a tandem would only require $600 \mathrm{kV}$. This kind of machine is envisaged as an intermediate step in a project under development. ${ }^{8}$ In addition, the

Table 3 - For different neutron producing reactions the table lists the threshold and some bombarding energies, the corresponding total thick target neutron production, the percentage for which the maximum neutron energy is less than $1 \mathrm{MeV}$, and the maximum and minimum neutron energies (14Colonna et al. 1999). For the 7Li(p,n)7Be reaction, En,max and $\mathrm{En}, \mathrm{min}$ correspond to ${ }^{7} \mathrm{Be}$ in its ground state.

\begin{tabular}{|c|c|c|c|c|c|c|}
\hline Reaction & $E_{\text {th }}(\mathrm{MeV})$ & $E_{\text {in }}(\mathrm{MeV})$ & $\begin{array}{c}\text { Total production } \\
\text { (n/mAs) }\end{array}$ & $\begin{array}{l}\text { Fraction } \\
E_{\mathrm{n}}<1 \mathrm{MeV}\end{array}$ & $E_{\mathrm{n}, \max }(\mathrm{keV})$ & $E_{\mathrm{n}, \min }(\mathrm{keV})$ \\
\hline \multirow[t]{5}{*}{${ }^{7} \mathrm{Li}(\mathrm{p}, \mathrm{n})^{7} \mathrm{Be}$} & 1.880 & 1.880 & 0 & $100 \%$ & 30 & 30 \\
\hline & & 1.890 & $6.3 \times 10^{9}$ & $100 \%$ & 67 & 7 \\
\hline & & 2.300 & $5.8 \times 10^{11} a$ & $100 \%$ & 573 & 141 \\
\hline & & 2.500 & $9.3 \times 10^{11 a}$ & $100 \%$ & 787 & 240 \\
\hline & & 2.800 & $1.4 \times 10^{12 b}$ & $92 \%$ & 1100 & 395 \\
\hline \multirow[t]{3}{*}{${ }^{9} \mathrm{Be}(\mathrm{p}, \mathrm{n}){ }^{9} \mathrm{~B}$} & 2.057 & 2.057 & 0 & $100 \%$ & 20 & 20 \\
\hline & & 2.500 & $3.9 \times 10^{10}$ & $100 \%$ & 574 & 193 \\
\hline & & 4.000 & $1.0 \times 10^{12}$ & $50 \%$ & 2117 & $73^{d}$ \\
\hline \multirow[t]{2}{*}{${ }^{9} \mathrm{Be}(\mathrm{d}, \mathrm{n}){ }^{10} \mathrm{~B}$} & 0 & $1.450^{c}$ & $1.6 \times 10^{11}$ & $69 \%$ & $5763^{e}$ & $225^{f}$ \\
\hline & & 1.500 & $3.3 \times 10^{11}$ & $50 \%$ & $5815^{e}$ & $271^{f}$ \\
\hline${ }^{13} \mathrm{C}(\mathrm{d}, \mathrm{n}){ }^{14} \mathrm{~N}$ & 0 & 1.500 & $1.9 \times 10^{11}$ & $70 \%$ & 6772 & $87^{g}$ \\
\hline
\end{tabular}

a Average between the values reported in Colonna et al. ${ }^{14}$ and Lee and Zhou. ${ }^{12}$

b Allen and Beynon. ${ }^{15}$

c Capoulat et al. ${ }^{16} 8 \mu \mathrm{m}$ thick target.

d Population of $1.5 \mathrm{MeV}$ excited state in ${ }^{9} \mathrm{~B}$.

e Population of the ground state of ${ }^{10} \mathrm{~B}$.

$\mathrm{f}$ Population of $5.11 \mathrm{MeV}$ state in ${ }^{10} \mathrm{~B}$.

$g$ Population of $6.446 \mathrm{MeV}$ state in ${ }^{14} \mathrm{~N}$. 
thermomechanical properties of Be are far superior to those of Li: a melting point of $1287 \mathrm{~K}$ and a thermal conductivity of $190 \mathrm{~W} \mathrm{~m}^{-1} \mathrm{~K}^{-1}$. A very significant advantage over the Li target is the fact that there is no residual radioactivity for Be. This reaction has also been thoroughly studied in connection with epithermal deep-seated tumor treatment with very encouraging results. ${ }^{16}$

To complete the discussion of the reactions shown in Table 3 we have to consider carbon as a target, which has excellent thermomechanical properties: a melting point of $3550 \mathrm{~K}$ and a thermal conductivity of $230 \mathrm{~W} \mathrm{~m}^{-1} \mathrm{~K}^{-1}$. It is a very stable material and the construction of a target is relatively simple. The ${ }^{12} \mathrm{C}(d, n)^{13} \mathrm{~N}$ reaction is not competitive due to its low neutron production but ${ }^{13} \mathrm{C}(d, n)^{14} \mathrm{~N}$ at $1.5 \mathrm{MeV}$ bombarding energy is characterized by a relatively large yield with interesting spectral features for AB-BNCT (low average neutron energies). This reaction has been studied both in Refs. 14, 20 and there is promise here in the case of low energy machines.

\section{Accelerators and facilities}

In spite of the long history of BNCT there has not been to date a single accelerator-based facility with the required features to carry out a BNCT clinical program in an optimized way. There are different types of accelerators ranging from low energy electrostatic machines to higher energy cyclotrons and to still much higher energy Linacs or synchrotrons, which are being considered for neutron production and BNCT. However, these latter machines produce neutrons with energies far too high for BNCT purposes and while "brute force" moderation can be applied (namely large enough moderation assemblies), high energy neutron tails do survive to some extent and activation also becomes a matter of concern. In addition these facilities may lend themselves for experimental programs but are unlikely to provide the optimal solution in terms of space and cost for BNCT to become a widespread hospital-based modality. Hence we shall here limit the discussion to ongoing attempts to built and develop high current (beyond the $\mathrm{mA}$ range) proton or deuteron accelerators of a few $\mathrm{MeV}$ to be used in connection with one of the reactions discussed above. Several of these machines have been and still are electrostatic and we shall start with them.

\subsection{Electrostatic accelerators}

A currently active AB-BNCT program is based around a $3 \mathrm{MV}$ Dynamitron accelerator in the School of Physics and Space Research at the University of Birmingham, UK ${ }^{21}$ (Green 1998). It is a single-ended machine enclosed in an SF6-filled pressurized vessel and the high voltage is generated through rectified $\mathrm{RF}$ power. At Birmingham this machine operates at $2.8 \mathrm{MV}$ and $1-2 \mathrm{~mA}$ and is devoted to multiple aspects of the AB-BNCT activity. ${ }^{3}$ It operates with a heavy water submerged jet cooled solid Li target ${ }^{22}$ and a Fluental-based beam shaping assembly (BSA) with a beam port at $90^{\circ}$ to the vertical beam direction. In order to conduct an optimal clinical program this facility would need an upgrade in terms of beam current. This same machine, with an upgraded ion source, is proposed as the core of a BNCT facility which is intended to operate at $2.8 \mathrm{MeV}$ and
$20 \mathrm{~mA}$ on a thin solid Li target at about $0.5 \mathrm{~kW} \mathrm{~cm}^{-2}$ power density. ${ }^{23}$

Another facility under development is based on a vacuum insulated compact tandem at the Budker Institute of Nuclear Physics in Novosibirsk, Russia. ${ }^{24}$ The goal for this facility is the production of near-threshold neutrons from the $\mathrm{p}+{ }^{7} \mathrm{Li}$ reaction at about $1.9 \mathrm{MeV}$ and currents up to $10 \mathrm{~mA}$. First low current tests have been performed. ${ }^{25}$ Progress has been made in the design and construction of a solid Li target which can be evaporated within the vacuum of the beam line. ${ }^{26}$ To date the maximum currents achieved ${ }^{1}$ are at about $2 \mathrm{~mA}$.

There is also another installation under development around a high current cascade generator ${ }^{2}$ at the IPPE, Obninsk, Russia, which has so far operated at $2.3 \mathrm{MeV}$ and $3 \mathrm{~mA}$.

Finally, a project to build a Tandem-ElectroStaticQuadrupole (TESQ) accelerator facility is under development in Argentina ${ }^{8}$ based on the ESQ concept. The machine being designed and constructed is a folded TESQ with a terminal of up to 1.2 MV intended to work in air, to avoid the need for a pressure vessel and for an insulating gas installation. The project aims at developing a machine capable of delivering a proton beam of about $2.4 \mathrm{MeV}$ and $30 \mathrm{~mA}$ to irradiate a $\mathrm{Li}$ metal target in order to produce a high-quality therapeutic neutron beam (i.e., with the least possible fast neutron contamination) after appropriate beam shaping. Such a facility, in combination with an optimized beam shaping assembly has been shown to be able to deliver treatments of comparable quality of the best present-day reactors. ${ }^{27-29}$ As an intermediate step, a smaller machine, a folded TESQ with a terminal at $700 \mathrm{kV}$ is also being developed to be used with the $\mathrm{Be}(\mathrm{d}, \mathrm{n})$ reaction. ${ }^{8}$

\subsection{RF Electrodynamic machines}

There are presently several ongoing projects to develop ABBNCT facilities based on radiofrequency machines. The first one to be mentioned, currently in its final construction phase, is the AB-BNCT project at the Laboratori Nazionali de Legnaro (LNL) of the Italian INFN organization based on a high intensity radiofrequency quadrupole operating at 4-5 MeV proton energy and $30 \mathrm{~mA}$ and intended to be used, with the ${ }^{9} \mathrm{Be}(\mathrm{p}, \mathrm{xn})$ reaction, for the development of a thermal neutron source for the treatment of skin melanoma. ${ }^{6}$

The second project is based on a superconducting Linac, currently installed at the Soreq research center, in Israel. The high intensity proton beam (of about $2 \mathrm{MeV}$ and $2 \mathrm{~mA}$ ) will be converted in a liquid Li target configured as a windowless forced flowing Li jet. ${ }^{5}$

These interesting projects are based on machines which are likely to be more expensive and complex than electrostatic ones for hospital-based facilities.

A $30 \mathrm{MeV}$ proton cyclotron installed at Kyoto University in combination with a Be target ${ }^{4}$ has already been mentioned. Clinical work has started in this facility.

Additionally, there is a project under development based on a RFQ+DTL near to Tsukuba. ${ }^{7}$ This machine is intended to produce an $8 \mathrm{MeV}, 10 \mathrm{~mA}$ proton beam to impinge on a $\mathrm{Be}$ target. 


\section{Summary and conclusions}

The advancement of BNCT requires neutron sources suitable for installation in hospital environments. Low-energy particle accelerators are most appropriate for this purpose. Furthermore, it is highly likely that the presence of these devices in specialized health-care institutions may be decisive for the future of BNCT. Major advantages of Accelerator-Based BNCT (AB-BNCT) over reactor-based neutron sources are: (a) The potential for siting within a hospital. (b) Less radiation hazards. (c) Larger simplicity in licensing, installation and maintenance. (d) Substantially lower capital expense than that associated with the installation of a reactor system in or near a hospital. (e) The neutron energy spectrum from certain nuclear reactions is much "softer" (less energetic) than the one coming from fission, which makes it easier to generate the "ideal" epithermal neutron spectrum needed to treat a deep seated tumor, and hence the quality of the neutron field can be designed to significantly exceed the quality of the neutron field for reactor-based neutron sources. Also nuclear reactions with harder neutron spectra have been shown to deliver acceptable treatments.

This work aims at giving an updated report of the worldwide status of Accelerator-Based BNCT (AB-BNCT) covering both $\mathrm{p}$ or $\mathrm{d}$ induced neutron producing reactions. The activity in accelerator development for AB-BNCT worldwide is described. Projects in Russia, UK, Italy, Japan, Israel, and Argentina to develop AB-BNCT around different types of accelerators are briefly presented. The endothermic nuclear reactions ${ }^{7} \mathrm{Li}(\mathrm{p}, \mathrm{n}){ }^{7} \mathrm{Be}$ and ${ }^{9} \mathrm{Be}(\mathrm{p}, \mathrm{n}){ }^{9} \mathrm{~B}$ and the exothermic reaction ${ }^{9} \mathrm{Be}(\mathrm{d}, \mathrm{n})^{10} \mathrm{~B}$ are compared. In addition to having much better thermo-mechanical properties than $\mathrm{Li}, \mathrm{Be}$ as a target, for both proton and deuteron induced reactions, leads to stable residual products. This is a significant advantage for a hospital-based facility. ${ }^{9} \mathrm{Be}(\mathrm{p}, \mathrm{n}){ }^{9} \mathrm{~B}$ needs at least 4-5 MeV bombarding energy to have a sufficient yield, while ${ }^{9} \mathrm{Be}(\mathrm{d}, \mathrm{n})^{10} \mathrm{~B}$ can be utilized at about $1.4 \mathrm{MeV}$, implying the smallest possible accelerator. This reaction operating with a thin, $8 \mu \mathrm{m}$, target can produce a sufficiently soft spectrum to be viable for AB-BNCT. The machines considered in combination with ${ }^{7} \mathrm{Li}(\mathrm{p}, \mathrm{n}){ }^{7} \mathrm{Be}$ and ${ }^{9} \mathrm{Be}(\mathrm{d}, \mathrm{n})^{10} \mathrm{~B}$ are electrostatic single ended or tandem accelerators in the $1.4-2.8 \mathrm{MeV}$ bombarding energy range. Also, electrodynamic machines of the RFQ+DTL (radiofrequency quadrupoles plus drift tube Linacs) type are considered for ${ }^{7} \mathrm{Li}(\mathrm{p}, \mathrm{n}){ }^{7} \mathrm{Be}$ and ${ }^{9} \mathrm{Be}(\mathrm{p}, \mathrm{n}){ }^{9} \mathrm{~B}$ in the $1.9-8 \mathrm{MeV}$ energy range.

The endothermic reaction ${ }^{7} \mathrm{Li}(\mathrm{p}, \mathrm{n})^{7} \mathrm{Be}$ at proton energies around $2.3 \mathrm{MeV}$ and currents in the $20-30 \mathrm{~mA}$ range coupled to appropriate beam shaping assemblies, with either solid or liquid Li targets provides one of the best solutions for the production of epithermal neutron beams for treatment of deep-seated tumors. Near-threshold operation with this reaction is also likely to be a good option. However, a Li-based target poses significant technological challenges. Hence, Be has been considered as an alternative target, both in combination with $(\mathrm{p}, \mathrm{n})$ and $(\mathrm{d}, \mathrm{n})$ reactions. In particular, ${ }^{9} \mathrm{Be}(\mathrm{d}, \mathrm{n}){ }^{10} \mathrm{~B}$ at about $1.4 \mathrm{MeV}$, in combination with a thin target has been shown to be a realistic option for the treatment of deep-seated lesions.

\section{Conflict of interest}

None declared.

\section{Financial disclosure}

Financial support by CONICET (PIP 316) and UNSAM is kindly acknowledged.

\section{REFERENCES}

1. Aleynik V, Bayanov B, Burdakov A, et al. BINP accelerator based epithermal neutron source. Appl Radiat Isot 2011;69:1639-41.

2. Kononov OE, Kononov VN, Bokhovko MV, et al. Optimization of an accelerator-based epithermal neutron source for neutron capture therapy. Appl Radiat Isot 2004;61: 1009-13.

3. Ghani Z, Green S, Wojnecki C, et al. BNCT beam monitoring, characterization and dosimetry. In: Proceedings of the 13th international congress on neutron capture therapy. ENEA. 2008. p. 647-9, and references therein.

4. Tanaka H, Sakurai Y, Suzuki M, et al. Experimental verification of beam characteristics for cyclotron-based epithermal neutron source (C-BENS). Appl Radiat Isot 2011;69:1642-5;

Tanaka H, Sakurai Y, Suzuki M, et al. Current status of cyclotron-based epithermal neutron source for BNCT In the front edge of BNCT development. In: Proceedings of Sixth Young Researchers BNCT Meeting. 2011., ISBN 978-986-03-0321-6 p. 246-9.

5. Halfon S, Paul M, Arenshtam A, et al. High power liquid-lithium target prototype for accelerator-based boron neutron capture therapy. ARI 2011;69:1654-6, and references therein.

6. Ceballos C, Esposito j, Agosteo S, et al. Towards the final BSA modeling for the accelerator-driven BNCT facility at INFN LNL. ARI 2011;69:1660-3.

7. Kumada H, Matsumura A, Sakurai H, et al. New challenge for advanced BNCT in University of Tsukuba. In the front edge of BNCT development. In: Proceedings of Sixth Young Researchers BNCT Meeting. 2011., ISBN 978-986-03-0321-6 p. 132-6.

8. Kreiner AJ, Castell W, Baldo M, et al. Development of a tandem-electrostatic-quadrupole facility for accelerator-based boron neutron capture therapy. ARI 2011;69:1672-5, and references therein;

Kreiner AJ, Baldo M, Bergueiro, et al. Accelerator-based BNCT. Appl Radiat Isot 2014;88:185-9, and references therein.

9. Kononov VN, Androsenko PA, Bohovko MV, et al. ${ }^{7} \mathrm{Li}(\mathrm{p}, \mathrm{n})^{7} \mathrm{Be}$ reaction near the threshold: the prospective neutron source for BNCT. In: Proceedings of the 1st international workshop on accelerator-based neutron sources for BNCT, vol. 2. 1994. p. 477-83.

10. Kobayashi T, Bengua G, Tanaka K. Neutrons for BNCT from the near threshold ${ }^{7} \mathrm{Li}(\mathrm{p}, \mathrm{n})^{7} \mathrm{Be}$ on a thick Li target. In: Proceedings of the 13th international congress on neutron capture therapy, ENEA. 2008. p. 478-81, and references therein.

11. Lee CL, Zhou XL. Thick target neutron yields for the ${ }^{7} \mathrm{Li}(\mathrm{p}$, n) ${ }^{7}$ Be reaction near threshold. Nucl Instrum Methods Phys Res 1999;B152:1-11.

12. Liskien $H$, Paulsen A. Neutron production cross section and energies for the reactions ${ }^{7} \mathrm{Li}(\mathrm{p}, \mathrm{n})^{7} \mathrm{Be}$ and ${ }^{7} \mathrm{Li}(\mathrm{p}, \mathrm{n})^{7} \mathrm{Be}$. At Data Nucl Data Tables 1975;15:57-84 
13. Burlon AA, Kreiner AJ, Valda AA, et al. Optimization of a neutron production target and a beam shaping assembly based on the ${ }^{7} \mathrm{Li}(\mathrm{p}, \mathrm{n})$ reaction for BNCT. Nucl Instrum Methods Phys Res 2005;B229:144-56, and refs. therein.

14. Colonna N, Beaulieu L, Phair L, et al. Measurements of low-energy $(\mathrm{d}, \mathrm{n})$ reactions for BNCT. Med Phys 1999;26(5):793-8.

15. Allen DA, Beynon TD. A design study for an accelerator-based epithermal neutron beam for BNCT. Phys Med Biol 1995;40:807-21.

16. Capoulat ME, Minsky DM, Kreiner AJ. Applicability of the ${ }^{9} \mathrm{Be}(\mathrm{d}, \mathrm{n}){ }^{10} \mathrm{~B}$ reaction to $\mathrm{AB}-\mathrm{BNCT}$ skin and deep tumor treatment. ARI 2011;69:1684-7;

Capoulat ME, Minsky DM, Kreiner AJ. Epithermal neutron sources based on ${ }^{9} \mathrm{Be}(\mathrm{d}, \mathrm{n})^{10} \mathrm{~B}$. In the front edge of BNCT development. In: Proceedings of Sixth Young Researchers BNCT Meeting. National Tsing Hua University; 2011., ISBN 978-986-03-0321-6 p. 33-41;

Capoulat ME, Minsky DM, Kreiner AJ. Computational assessment of deep-seated tumor treatment capability of the ${ }^{9} \mathrm{Be}(\mathrm{d}, \mathrm{n}){ }^{10} \mathrm{~B}$ reaction for accelerator-based boron neutron capture therapy (AB-BNCT). Phys Med 2013;30:133-46.

17. Kobayashi T, Miura K, Hayashizaki N, Aritomi M. Development of liquid-lithium film jet-flow for the target of ${ }^{7} \mathrm{Li}(\mathrm{p}, \mathrm{n}){ }^{7}$ Be reactions for BNCT. Appl Radiat Isot 2013, http://dx.doi.org/10.1016/j.apradiso.2013.12.013.

18. Burlon AA, del T, Roldan V, et al. Nuclear reactions induced by deuterons and their applicability to skin tumor treatment through BNCT. Nucl Instrum Methods Phys Res 2008;B266:4903-10.

19. Guzek J, Tapper U, McMurray W, et al. Characterization of the ${ }^{9} \mathrm{Be}(\mathrm{d}, \mathrm{n}){ }^{10} \mathrm{~B}$ reaction as a source of neutrons employing commercially available radiofrequency quadrupole (RFQ) linacs. In: Proceedings of the SPIE, vol. 2867. The International Society for Optical Engineering; 1997. p. 509-12.

20. Burlon AA, Kreiner AJ, White SM, et al. In-phantom dosimetry using the ${ }^{13} \mathrm{C}(\mathrm{d}, \mathrm{n}){ }^{14} \mathrm{~N}$ reaction for BNCT. Med Phys 2001;28:796-803

21. Green S. Developments in accelerator based BNCT. Radiat Phys Chem 1998;51(4-6):561-9.

22. Scott MC. Private communication; 2008.

23. Forton E, Stichelbaut F, Cambriani A, et al. Overview of the IBA accelerator-based BNCT system. In: Proceedings of the 13th international congress on neutron capture therapy, ENEA. 2008. p. 530-4.

24. Bayanov BF, Belov VP, Bender EDED, et al. Accelerator-based neutron source for the neutron-capture and fast neutron therapy at hospital. Nucl Instrum Methods Phys Res 1998;A413:397-426.

25. Bayanov B, Burdakov A, Chudaev V, et al. First neutron generation in the BINP accelerator based neutron source. In: Proceedings of the 13th international congress on neutron capture therapy, ENEA. 2008. p. 514-7.

26. Taskaev S, Bayanov B, Belov V, et al. Development of Li target for AB-BNCT. In: Advances in NCT. Osaka: Neutrino; 2006. p. 292-5, and references therein.

27. Burlon AA, Kreiner AJ. A comparison between a TESQ accelerator and a reactor as a neutron source for BNCT. Nucl Instrum Methods Phys Res 2008;B266:763-71.

28. Minsky DM, Kreiner AJ, Valda AA. AB-BNCT BSA based on the ${ }^{7} \mathrm{Li}(\mathrm{p}, \mathrm{n})^{7}$ Be reaction optimization. ARI 2011;69:1668-71, and references therein.

29. Herrera MS, González SJ, Minsky DM, Kreiner AJ. Evaluation of performance of an accelerator-based BNCT facility for the treatment of different tumor targets. Phys Med 2013;29:436-46, and references therein. 